\title{
Why do older drivers give up driving?
}

Reprint from Accident Analysis and Prevention,

Vol. 30, No. 3, pp. 305-312, 1998

Liisa Hakamies-Blomqvist, VTI and

Barbro Wahlström, University of Helsinki, Finland

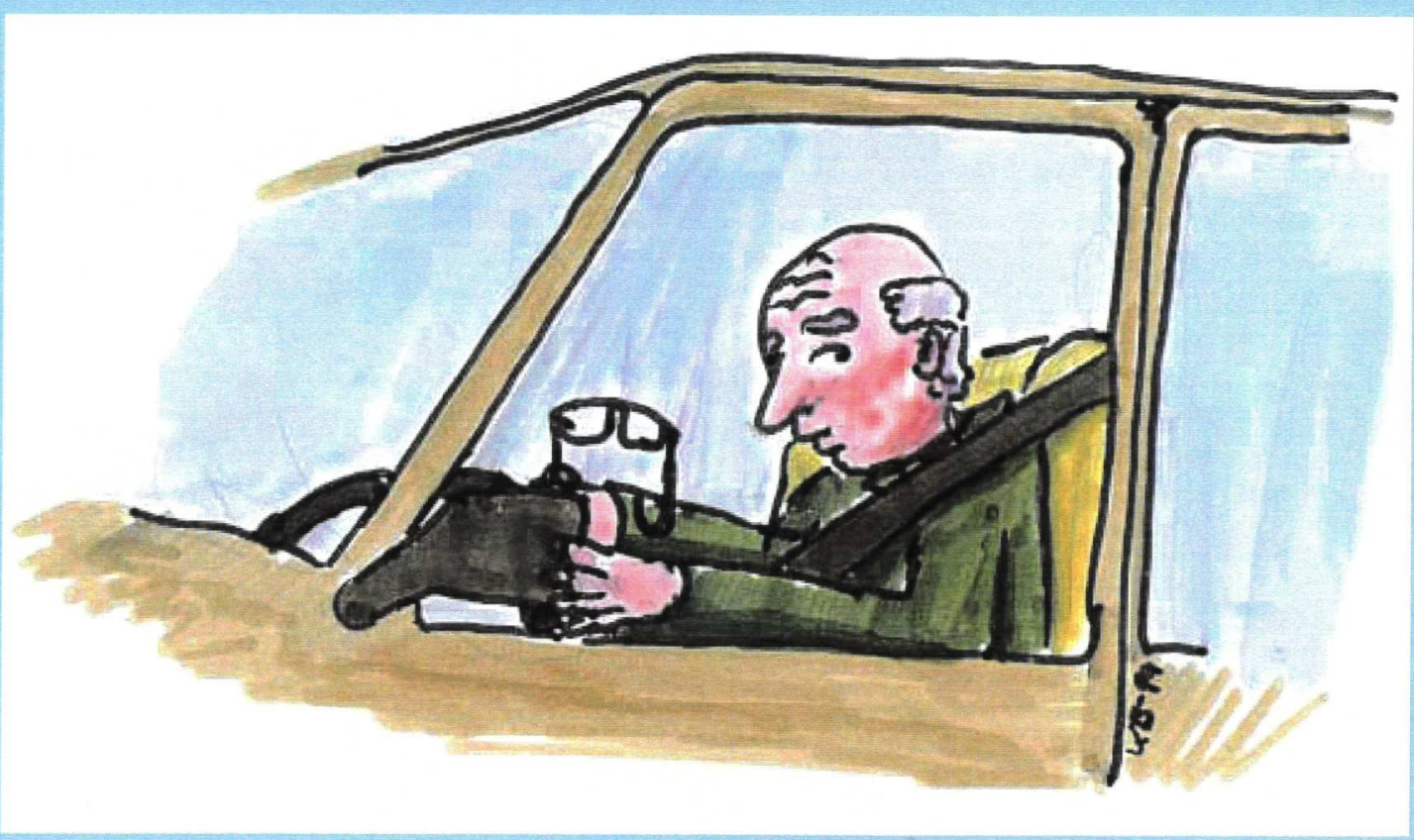




\section{VTI särtryck 321 - 1999}

\section{Why do older drivers give up driving?}

Reprint from Accident Analysis and Prevention, Vol. 30, No. 3, pp. 305-312, 1998

Liisa Hakamies-Blomqvist, VTI and

Barbro Wahlström, University of Helsinki, Finland 


\title{
WHY DO OLDER DRIVERS GIVE UP DRIVING?
}

\author{
LIISA HAKAMIES-BLOMQVIST ${ }^{1,2, *}$ and BARBRo WAHLSTRÖM ${ }^{1}$
}

\author{
${ }^{1}$ Department of Psychology, P.Box 13, 00014 University of Helsinki, Helsinki, Finland \\ and ${ }^{2}$ Swedish National Road and Transport Research Institute (VTI), SE-58195 Linköping, Sweden
}

\begin{abstract}
All Finnish license holders aged 70 years (from the cohort born in 1922) who did not renew their driver license, and a corresponding comparison group among those who did renew their license, were contacted by a mail survey. They were asked about their reasons to continue or to stop driving, about their current living conditions and health status, and about some aspects of their driving behavior. The reasons to stop or to continue driving were different for men and women. Male drivers considered more frequently than female drivers the use of private car a necessity. Male respondents who did not renew their license (ex-drivers) were less healthy than those who did renew their license (drivers). The most frequently indicated reason to stop driving among men was deteriorated health. However, only $6.9 \%$ of the ex-drivers had received professional advice to stop driving. For most of these cases, this advice had been given by the physician responsible for the treatment of their main illness. The change in health condition was related to a shift in driving activity: those still driving were in best health, followed by those ex-drivers who stopped driving at the age of 70 years, while those who had stopped driving at an earlier age had the highest number of illnesses and had most frequently experienced a deterioration of their health status during the last year. Both male and female ex-drivers reported more feelings of stress in traffic and more frequent avoidance of certain traffic situations than drivers. Women reported more frequently traffic-related stress and avoidance than men as both drivers and ex-drivers. (C) 1998 Elsevier Science Ltd. All rights reserved
\end{abstract}

Keywords - Aging, Avoidance, Driver, License, Screening, Stress

\section{INTRODUCTION}

The area of aging and driving has been of interest in transport research since the late 1960s [for a review, see Hakamies-Blomqvist (1996)]. Even though older drivers as a group are considered cautious and relatively safe drivers, they have on group level higher accident rates per mileage than middle-age drivers, equaling those of the youngest driver categories (Cerrelli, 1989; Evans, 1991). In recent research literature there seems to be an increasing consensus that the problem is not age per se. Rather, the group level risk increase is attributed to those subgroups of older drivers who have illness-related functional impairments affecting their driving ability (Janke, 1994; Lundberg et al., 1997; Waller, 1992). Instead of an age problem, we thus have an age-related illness problem, given the with age increasing prevalence of many illnesses affecting driving ability. How to identify the subgroups of older drivers with increased accident risk, and what to do about them, is one of the major challenges in older driver research (Hakamies-Blomqvist et al., 1997).

*Corresponding author. Tel.: 003589 19123403; fax: 003589 19123404; e-mail: liisa.hakamies-blomqvist@helsinki.fi
In many countries, different age-related screening practices are used. Such screening mostly consists of different combinations of the following items: medical evaluations; vision tests; knowledge tests; and onroad tests. Very little is, however, known about the actual screening effect of such practices, and even less about their possible traffic safety effects. In Australia, the state of Victoria, the only one with no screening for older drivers, has the best safety situation for this driver group (Torpey, 1986). In contrast, in the U.S., the states having obligatory vision controls have slightly lower accident rates than those without (Levy et al., 1995). It is not clear, however, whether this effect is due to the exclusion of those with bad vision from the driver population or to a better vision correction of active drivers and a higher utilization rates for glasses among them. On the other hand, when the State of California replaced the standard in-person renewal process (including vision and knowledge test and sometimes even a road test) with an administrative license extension by mail, no changes in the violation or accident rates of older drivers were observed. In Israel, the license renewal process of drivers aged 65 years or more was followed up in 1980 (Zaidel and Hocherman, 1986). Of this group, $96 \%$ of this group renewed their license, and 
none of the applicants were formally denied a license on the grounds of the results of the renewal process. Of those $4 \%$ who spontaneously renounced to license renewal, only $11 \%$ did it for reasons related to the renewal process itself. The authors conclude that this elaborate renewal process had no impact as a screening device.

In a comparative Finnish-Swedish study (Hakamies-Blomqvist et al., 1996), a different approach to evaluation was chosen, based on the fact that Finland has strict medical screening for older license holders (aged 70+) while Sweden has none. A comparison of population-related accident rates of Finnish and Swedish older drivers showed no safety effects of the Finnish screening (i.e. the age trends in older drivers' accident rates were similar in both countries). However, unprotected road users aged 65 years or more had twice the risk of dying in a traffic accident in Finland compared to Sweden. Thus, since the Finnish infrastructure is less favorable for unprotected road users, the screening may actually have a safety-decreasing effect while leading to a disadvantageous modal shift. Discussing their findings, the authors also state that the Finnish screening de facto has a very small actively screening effect, but that it leads to a self-screening, that is, a significant number of license holders spontaneously renounce to driving at the age of 70 . In this respect, the situation seems somewhat similar to the one reported from Israel.

As seen in the Israelian and Finnish examples, any screening practice of older drivers will have as by-product some amount of self-screening, that is, some older drivers will decide not to try to renew their license. In fact, this may even be the most important result of the screening. Therefore, it is important to understand how such spontaneous driving cessation affects the older driver population. The present study was designed to investigate which subgroups of drivers aged 70 years did not renew their license, and which ones did, and the reasons hereof. Without this information, it is not possible to evaluate the Finnish license renewal system's overall screening effect on the older driver population.

\section{MATERIALS AND METHODS}

Mail survey

A mail survey was sent to all Finnish license holders born in 1922 who did not renew their license at the age of 70 in $1992(N=3069$; 'ex-drivers'; XD), and to a random sample of license holders born in 1922 who did renew their license $(N=3073$; 'drivers', D). The respondents were asked about their driving habits, health and living conditions, and their reasons to stop driving or to continue having a license.

A total of 4168 questionnaires $(71.4 \%)$ were returned. After the removal of incomplete answers, the following analyses are based on 3811 cases (Table 1).

\section{Telephone interview}

A completing telephone interview was conducted 2 years later among those respondents who had reported that they had been advised by a physician to stop driving. The aim was to determine in which medical setting and based on which diagnosis this advice had been given. This information was attained for 54 of the 97 original respondents in this group.

\section{Statistical analysis}

For comparisons of subgroups defined by gender and/or driver status, one-way analysis of variance was used for continuous variables and Pearson's $\chi^{2}$ for categorized variables.

\section{RESULTS}

\section{Self-reported reasons to driving cessation or continuation}

While licensing rates were much lower for women in the study cohort (ca 25\%) than for men (ca 82\%), female license holders also stopped driving more often than men. The continuation rate was $67 \%$ for women and $88 \%$ for men. For those license holders who did renew their license (drivers), the reasons to do this differed between men and women. (The questions about reasons to stop or continue driving were formulated as lists of alternatives among which the respondents could choose one or more.) Sixtyfive percent of the male drivers and $43 \%$ of the female

Table 1. Response rates

\begin{tabular}{|c|c|c|c|c|c|c|}
\hline & \multicolumn{2}{|r|}{ Drivers } & \multicolumn{2}{|r|}{ Non-drivers } & \multicolumn{2}{|r|}{ Total } \\
\hline & Sample $N$ & Respiratory rate $N(\%)$ & Sample $N$ & Respiratory rate $N(\%)$ & Sample $N$ & Respiratory rate $N(\%)$ \\
\hline Men & 2445 & $1902(78.5)$ & 1375 & $483(34.5)$ & 3820 & $2385(62.4)$ \\
\hline Women & 628 & $512(81.7)$ & 1694 & 914 (53.9) & 2322 & $1426(61.4)$ \\
\hline Total & 3073 & $2414(79.2)$ & 3069 & $1397(45.2)$ & 6142 & $3811(62)$ \\
\hline
\end{tabular}


drivers considered the use of private car a necessity. Female drivers more frequently motivated their license renewal by occasional needs or a wish to retain the option to drive without any specific needs.

Even for those license holders who did not renew their license (ex-drivers), the reasons were different for men and women (Fig. 1). Men referred most often to health reasons $(41.4 \%)$, whereas the most frequent reason for women not to renew their license was that they already had stopped driving (55.7\%).
Since the female license holders of the study cohort are a small and highly selected group, the results concerning them are of limited generalizability. Therefore, in some analyses, only male respondents were included.

Of those the male respondents who did not renew their license, $40.2 \%$ had not been driving during the last 2 years (however, not all of these drivers had indicated this as a reason to stop having a license, as seen in Fig. 2). In some analyses, the following three

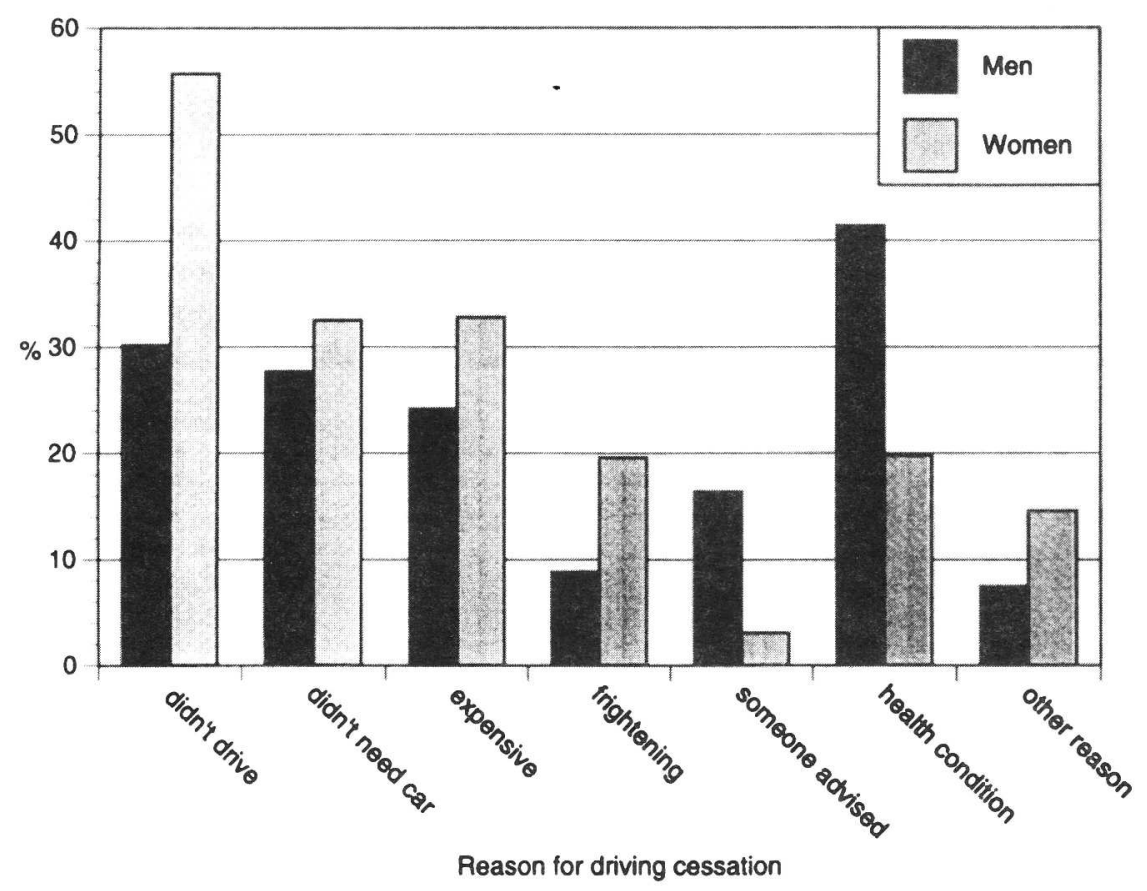

Fig. 1. Reasons for driving cessation by gender.

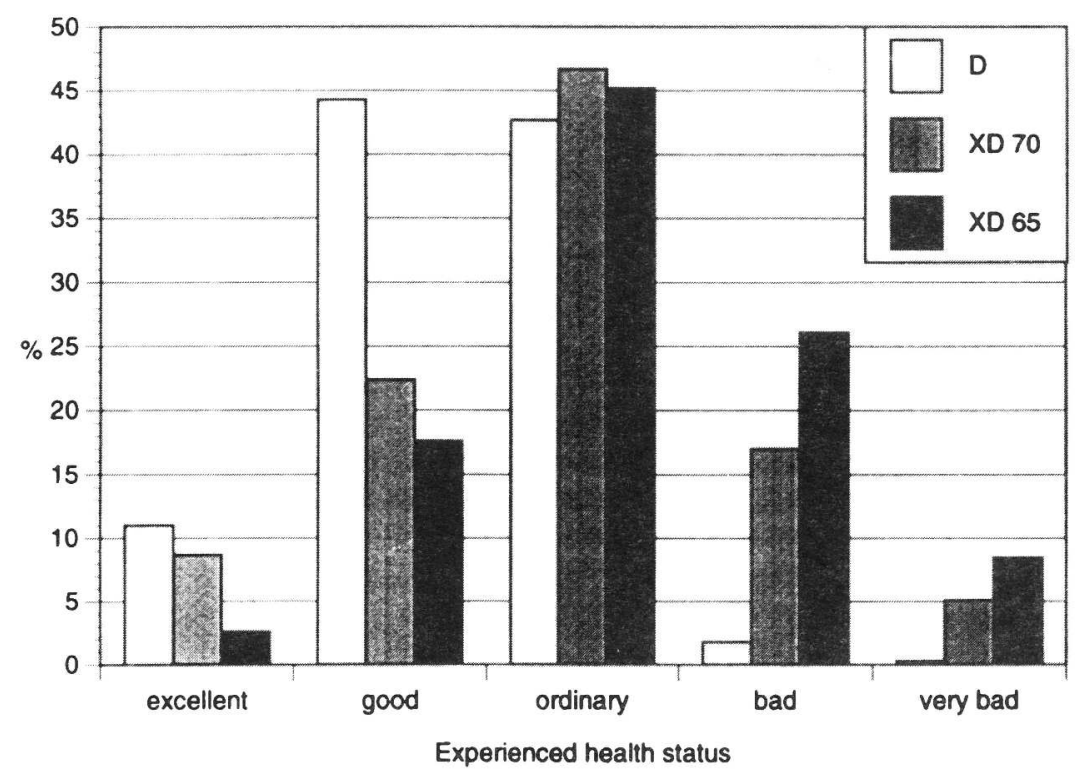

Fig. 2. Experienced health status in male drivers and ex-drivers. 
groups were therefore separated: male drivers (D); those male ex-drivers who stopped driving at the age of 70 (late ex-drivers; XD 70); and those male ex-drivers who had stopped driving earlier (early ex-drivers; XD 65).

Experienced health status in male drivers and ex-drivers. As shown above, the most commonly indicated reason of male license-holders to stop driving was deteriorated health. In accordance with this, there was a gradual shift in their experienced health status (Fig. 2). The health status of early ex-drivers was worst and that of still active drivers best $\left[\chi^{2}(8)=417.2 ; p<0.01\right]$.

\section{Prevalence of different illnesses in male drivers and} ex-drivers

An analogous difference in health status was attained when the respondents reported illnesses which had been diagnosed by a doctor. Ex-drivers were less healthy than drivers, that is, they had a higher prevalence of illnesses in most important diagnostic categories (Fig. 3). The mean number of reported illnesses was 1.36 for drivers and 2.61 for ex-drivers $[F(1)=278 ; p<0.01]$. Glaucoma, depression and neurological disorders differentiated best between the groups, while cancer and rheumatism did not affect driving activity.

The ex-drivers were not only less healthy than the drivers, their health condition was also less stable.
When asked about changes in health during the last year, $4.3 \%$ of the drivers and $25.2 \%$ of the ex-drivers reported that their health condition had deteriorated $\left[\chi^{2}(2)=212.2 ; p<0.01\right]$.

Living conditions of male drivers and ex-drivers. In line with the health findings, male drivers more frequently lived in their own homes than male ex-drivers (Table 2) $\left[\chi^{2}(4)=57.7 ; p<0.01\right]$. They were also more frequently married $(84.1 \%)$ than ex-drivers (78.4\%); in both groups similar portions were unmarried but ex-drivers were more often divorced or widowers $\left[\chi^{2}(4)=10.7 ; p<0.05\right]$.

Physician's advice to stop driving. Among the ex-drivers, there were 96 cases $(=6.9 \%$ of the ex-drivers) and among the drivers one case in which the license holder had been advised by a physician to stop driving (whether or not this advice had affected their decision was, however, not explicitly asked). The questionnaire provided no information about the

Table 2. Housing conditions of male drivers and ex-drivers

\begin{tabular}{lccr}
\hline \multicolumn{4}{c}{ Housing condition } \\
\hline Driver status & $\begin{array}{c}\text { Home with family } \\
\text { member } N(\%)\end{array}$ & $\begin{array}{c}\text { Home alone } \\
N(\%)\end{array}$ & $\begin{array}{c}\text { Institution } \\
N(\%)\end{array}$ \\
\hline Drivers & $1543(85.8)$ & $250(13.9)$ & $6(0.3)$ \\
Ex-drivers 70 & $218(79.9)$ & $43(15.8)$ & $12(4.4)$ \\
Ex-drivers 65 & $142(76.3)$ & $36(19.4)$ & $8(4.3)$ \\
\hline
\end{tabular}

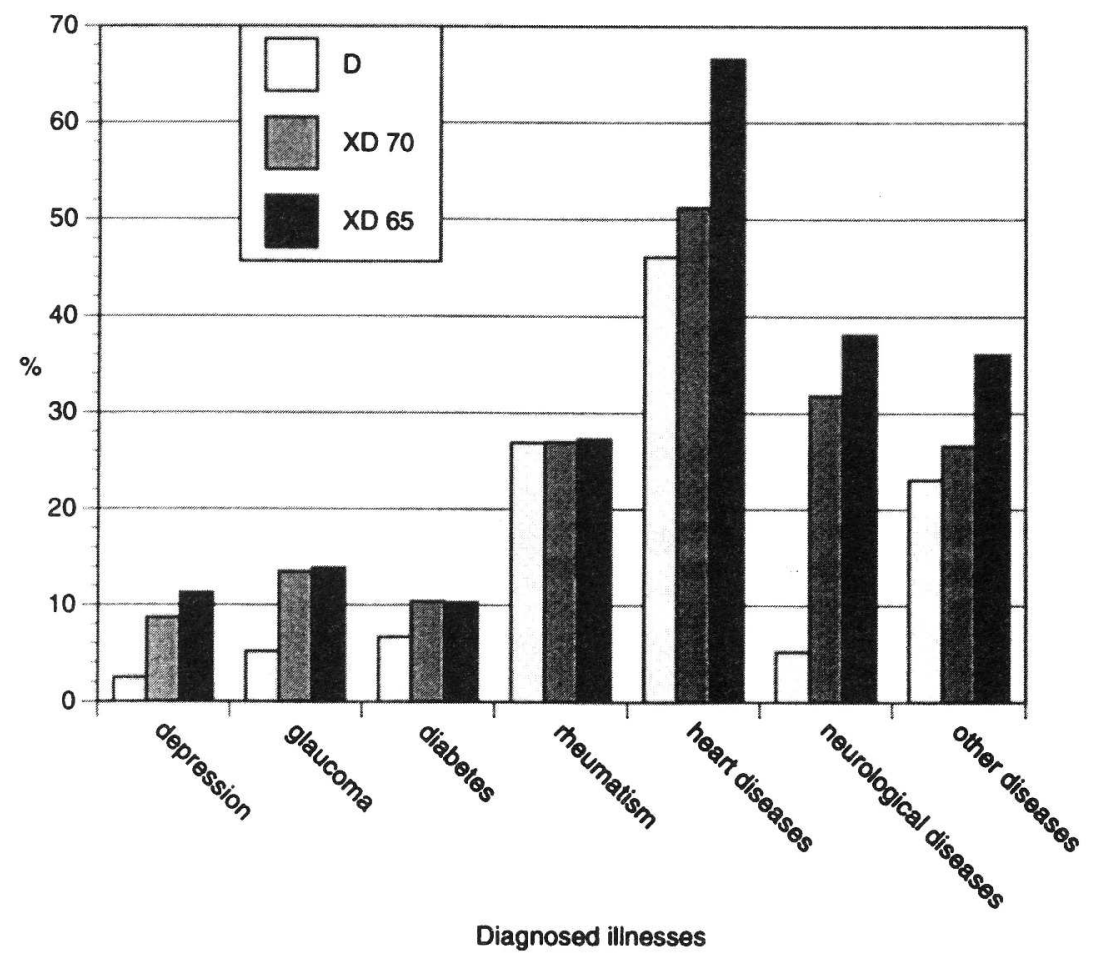

Fig. 3. Prevalence of different illnesses in male drivers and ex-drivers. 
medical setting in which the advice had been given or about the nature of health problems leading to such a medical opinion. Therefore, these persons were contacted for a completing telephone interview. If the person could not be reached, when possible, family members were asked about his/her illnesses and about the medical setting.

Information about the medical setting was available in 54 cases. Of these, $43(79.6 \%)$ had received the advice to stop driving in a normal clinical setting, that is, from their family physician or the physician responsible for the treatment of their illness. In 11 cases the advice had been given in connection with the obligatory health control for license renewal (one of these cases nevertheless continued having a license and driving her car). Vision deficits and stroke were the most commonly indicated health problems leading to the advice to stop driving. The drop-out among the original 96 cases was mainly due to the death of the person.

\section{Driver behavior}

Similar questions regarding driving behavior were asked from both drivers and ex-drivers. However, the ex-drivers were asked to answer on the basis of how their situation had been during their last year as active drivers.

The respondents who kept their driver license at the age of 70 years drove rather frequently. Of the male drivers $70.7 \%$ reported driving daily and $24.6 \%$ several times a week. The corresponding percentages for ex-drivers were 26.3 and $15.1 \%$, respectively. Among the drivers there were $0.5 \%$ and among the ex-drivers $37.1 \%$ who reported that they had stopped driving entirely.

The respondents were asked whether they avoided (yes or no) or had avoided while still driving certain traffic situations (slippery roads, rush hours, driving at night, driving in winter, driving in urban areas and driving on highways). The form of the resulting profile was approximately similar to all groups, but the levels differed (Fig. 4). Women reported avoidance for each situation significantly more frequently than men (tested for each situation by $\left.\chi^{2} ; p<0.01\right)$. Within gender groups, for most items, ex-drivers reported avoidance behavior more frequently than drivers. Male ex-drivers reported significantly $(p<0.01)$ more avoidance for driving in winter, driving in urban areas and driving on highways than male drivers. Within the female group, the difference between drivers and ex-drivers was statistically significant for driving in winter and driving in urban areas.

The respondents were also asked to rate the experienced stress connected to different traffic and road conditions. Specifically, the rating scale had for levels ('heavy stress', 'moderate stress', 'negligible stress' and 'no stress'), and the following items were rated: driving on slippery roadways, driving when tired, driving at night, coping with a competitive attitude among other drivers, driving during rush hours, driving in unfamiliar surroundings, driving long distances, coping with an overly cautious driving style among other drivers, overtaking, parking or reversing, driving in crossings, adjusting to the traffic flow, switching lanes, observing traffic signs, driving

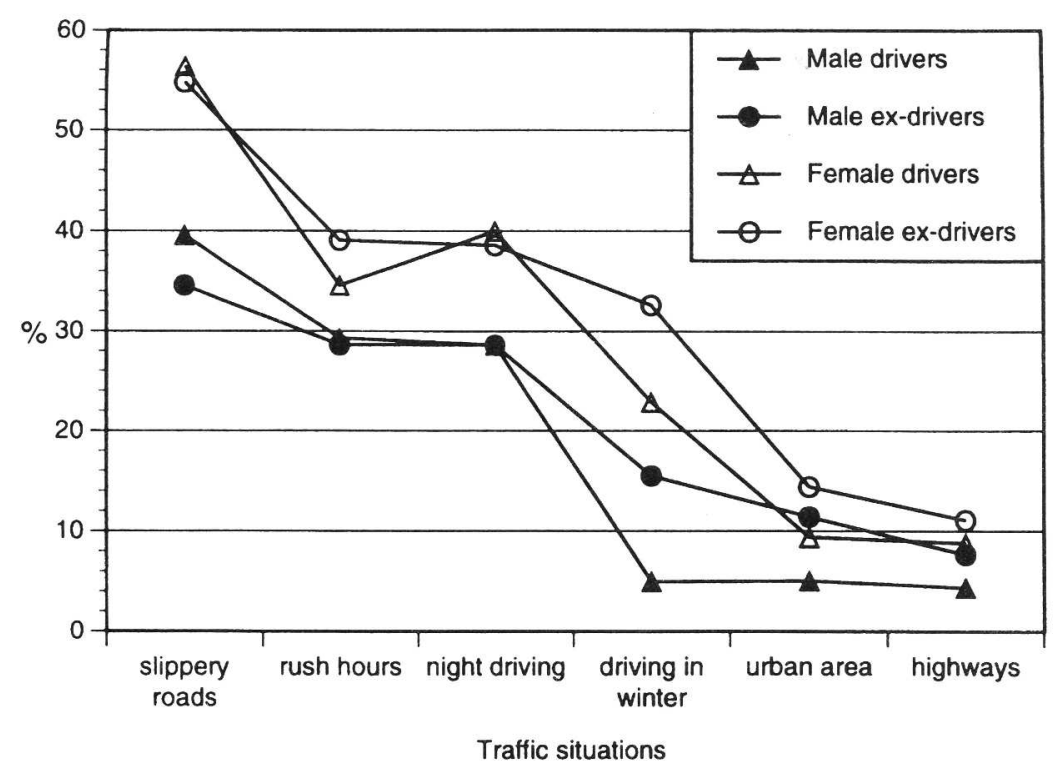

Fig. 4. Avoidance of difficult traffic situations by male and female drivers and ex-drivers. 
on highways and merging into a main road. For the statistical analysis, the categories of experienced stress were combined pairwise (heavy + moderate and negligible + none). For all the traffic and road conditions except driving long distances (Fig. 5), women reported more frequently feelings of moderate or heavy stress than men (all the situations were tested individually by $\chi^{2}, p<0.01$ ). Within the female group, ex-drivers reported more stress for all conditions except the overly cautious driving style of others. Among males, the overly cautious driving style of others and driving while tired were the only conditions for which ex-drivers did not report more stress feelings than drivers.

\section{DISCUSSION}

In the present study, driving cessation among the Finnish elderly appears as a spontaneous, gradual process, during which the older drivers become increasingly more vulnerable to difficulties in traffic, limit their driving in certain conditions, and drive progressively less than before. The further this process has gone at the official checkpoint of 70 years of age, the more likely it is that the driver decides not to renew his/her license. The reasons steering this decision making are somewhat different for men and women: women attribute less importance to the possibility of driving a car, while men mostly continue driving as long as their health allows them to do it.

Unlike earlier studies about driving cessation among elderly drivers, the present study has the advantage of being population-based, that is, our sample included all the ex-drivers in the Finnish cohort born in 1922 and a random sample of the corresponding drivers. The findings can therefore be considered highly reliable and representable, if not biased by a selective drop-out of some subgroups of respondents. While the response rates for drivers actually were high, that is, ca $80 \%$ in both men and women, the corresponding rates for ex-drivers were only $53.9 \%$ for women and $34.5 \%$ for men. In all studies of elderly populations, mortality and morbidity are, of course, two inevitable sources of drop-out in. The general mortality rate among Finnish men aged 70 years is ca $4 \%$, but since our findings showed that drivers are healthier than ex-drivers, the mortality rate should also be higher among ex-drivers. More important, however, is probably a drop-out of ex-drivers due to a higher prevalence of serious health

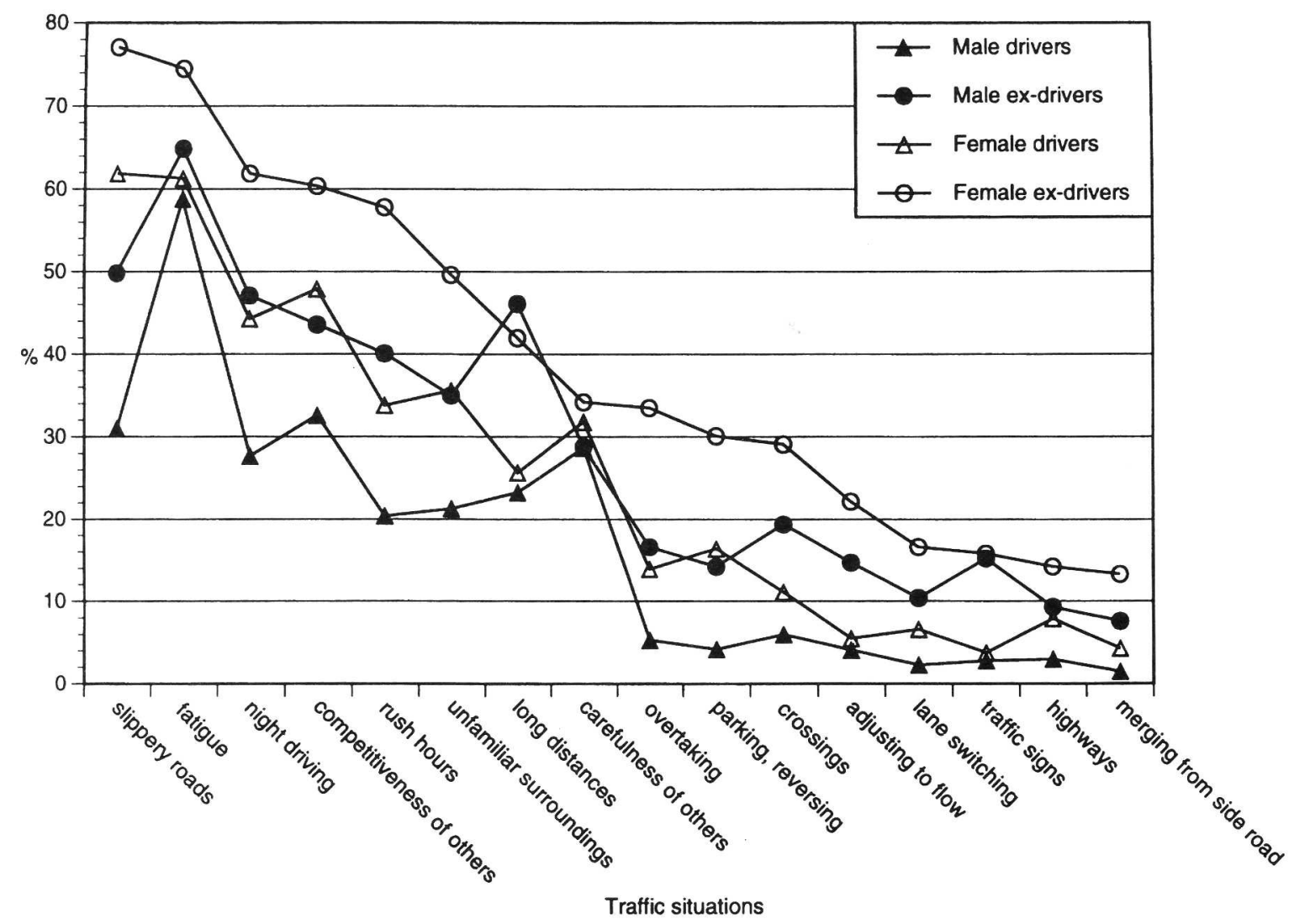

Fig. 5. Experience of stress connected to different traffic situations by male and female drivers and ex-drivers. 
problems, as well as to higher institutionalization rates among those ex-drivers who did not return the questionnaire. Since the drop-out of ex-drivers is likely to have lead to the exclusion from the study of the least healthy part of this group, the present findings are reliable in the sense that they tend to underestimate rather than overestimate the differences between drivers and ex-drivers.

The generalizability over time of the present findings regarding gender differences is more problematic. Given the low licensing rates among Finnish women born in 1922, the female drivers of the present study represent a small and highly selected fraction of their cohort. While our findings give a reliable account of the situation in Finland in 1993, it is likely that gender differences in driving cessation will diminish along with the growth of licensing rates among successive cohorts of women. The present findings are, however, in accordance with the existing literature on gender effects in older drivers. The reasons of older Finnish female drivers to continue or to stop driving reflect the smaller importance they attribute to driver license and private car use than their male counterparts. Similar observations have been reported by Rothe (1990). When gender differences are found, female drivers are in general described as more cautious and less self-assured than male drivers (McKenna et al., 1991). In the present study, all gender differences found were in accordance with this general statement. Women reported more avoidance behavior and more stress related to difficult driving conditions than men in both the driver and the ex-driver group.

For the female license holders, the screening effect of the Finnish system and its possible safety consequences seem practically nonexistent. Since most of the female ex-drivers did not drive anymore, the fact that they renounced to having a license did not affect the collective mileage of this age group. If some women were intimidated by the strict control system not to renew their license while still active drivers, there is no reason to believe that these women would have been at greater risk than others. As indicated by the study of Jones evaluating the advisory letters used in the Oregon Driver Improvement Program (Jones, 1997), authoritarian measures may be better to produce safety effects for men than for women.

In the male group of the present study, the gradual nature of driving cessation became well apparent. There was in all important variables a gradual shift from drivers to early ex-drivers reflecting the same trend of increasing problems. Those who had stopped driving earlier were the ones who had most illnesses, whose health conditions was most rapidly deteriorating, who were most often institutionalized, who felt most stressed in traffic, and who most frequently avoided difficult driving conditions. While health reasons are the main reason for men to stop driving, there effect thus is mediated progressively; that is, driving becomes gradually more straining, and is limited by the driver both qualitatively and quantitatively before he finally stops driving. These findings are in accordance with earlier studies based on different samples of older drivers (Marottoli et al., 1993; Persson, 1993; Rabbitt et al., 1996).

It is noticeable from the screening point of view that although health condition was a central determinator in decisions about continued driving, $<10 \%$ of the ex-drivers had been advised by a physician to stop driving. In addition, only $20 \%$ of these cases had received this advice in the official Finnish setting for obligatory medical control of older license holders. Since most of the drop-out in the telephone interview was due to mortality, the real percentage probably was even lower; those who were most seriously ill were most likely to get the advice to stop driving from the physician responsible for their medical treatment in a clinical setting. According to these results, the obligatory medical control included in the Finnish screening influences the decision making of only ca $1 \%$ of the cases where a license holder decides to stop driving at the age of 70 years.

In conclusion, more research is needed to develop scientifically sound ways of evaluating the safety and mobility effects of different screening practices. Given the gradual and spontaneous nature of driving cessation among most older drivers, the quest of screening devices with predictive power should be complemented with research efforts destined to develop methods to support the autonomous decision making of older drivers regarding driving cessation.

Acknowledgements - Support from the Swedish Communication Research Board, the Finnish Ministry of Transport, and the Finnish Traffic Safety Organization is gratefully acknowledged. The authors wish to thank Juha Luoma for his helpful suggestions on an earlier version of the present paper.

\section{REFERENCES}

Cerrelli, E. (1989) Older drivers, the age factor in traffic safety. (NHTSA Technical Report DOT HS 807 402): National Highway Traffic Safety Administration, Washington, DC.

Evans, L. (1991) Traffic Safety and the Driver. Van Nostrand Reinhold, New York.

Hakamies-Blomqvist, L. (1996) Research on older drivers: a review. IATSS Research 20, 91-101.

Hakamies-Blomqvist, L., Johansson, K., Lundberg, C. (1996) Medical screening of older drivers as a traffic safety measure - a comparative Finnish-Swedish eval- 
uation study. Journal of the American Geriatrics Society 44, 650-653.

Hakamies-Blomqvist, L., Johansson, K. and Lundberg, C. (1997) Letter to the Editor. Journal of the American Geriatric Society 45, 389.

Janke, M. K. (1994) Age-related disabilities that may impair driving and their assessment. (Report CALDMV-RSS-94-156): California State Department of Motor Vehicles, National Highway Traffic safety Administration, Sacramento, CA.

Jones, B. (1997) Age, gender and the effectiveness of highthreat letters: an analysis of Oregon's driver improvement. Accident Analysis and Prevention 29, 225-234.

Levy, D. T., Vernick, J. S. and Kim, A. H. (1995) Relationship between driver's license renewal policies and fatal crashes involving drivers 70 years or older. Journal of the American Medical Association 274, 1026-1030.

Lundberg, C., Johansson, K., Ball, K., Bjerre, B., Blomqvist, C., Braekhus, A., Brouwer, W., Bylsma, F., Carr, D. B., Englund, L., Friedland, R., HakamiesBlomqvist, L., Klemetz, G., O'Neill, D., Odenheimer, G. L., Rizzo, M., Schelin, M., Seideman, M., Tallman, K., Viitanen, M., Waller, P. F. and Winblad, B. (1997) Dementia and driving - an attempt at consensus. Alzheimer Disease and Associated Disorders 11, 28-37.
Marottoli, R. A., Ostfeld, A. M., Merrill, S. S., Perlman, G. D., Foley, D. J. and Cooney, L. M. (1993) Driving cessation and changes in mileage driven among elderly individuals. Journal of Gerontology: Social Sciences $\mathbf{4 8}$, S255-S260.

McKenna, F. P., Stanier, R. A. and Lewis, C. (1991) Factors underlying illusory self-assessment of driving skill in males and females. Accident Analysis and Prevention 23, 45-52.

Persson, D. (1993) The elderly driver: deciding when to stop. The Gerontologist 33, 88-91.

Rabbitt, P. A., Carmichael, A., Jones, S. and Holland, C. (1996) When and Why Older Drivers Give Up Driving. AA Foundation for Road Safety Research, Manchester.

Rothe, J. P. (1990) The Safety of Elderly Drivers. Transaction Publishers, London.

Torpey, S. E. (1986) License Re-testing of Older Drivers. Road Traffic Authority, Hawthorn.

Waller, J. A. (1992) Research and other issues concerning effects of medical condition on elderly drivers. Human Factors 34, 3-15.

Zaidel, D. M. and Hocherman, I. (1986) License renewal for older drivers: the effects of medical and vision tests. Journal of Safety Research 17, 111-116. 
VI FORSKAR FÖR ETT LIV I RÖRELSE

Statens väg- och transportforskningsinstitut (VTI) har kompetens och laboratorier för kvalificerade forskningsuppdrag inom transporter och samhällsekonomi, trafiksäkerhet, fordon, miljö samt för byggande, drift och underhăll av vägar och järnvägar.

The Swedish National Road and Transport Research Institute (VTI) has laboratories and know-how for advanced research commissions in transport and welfare economics, road safety, vehicles and the environment. It also has research capabilities for the construction, operation and maintenance of roads and railways.

\section{Adress}

Postal address

SE-581 95 Linköping, Sweden
Telefon

Telephone

Nat 013-20 4000

Int +4613204000
Fax

E-post

E-mail

Nat 013-14 1436

Int +4613141436 